\title{
Article
}

\section{The impact of Corona pandemic on consumer's food consumption - Vulnerability of households with children and income losses}

\author{
Adriano Profeta ${ }^{1, *(\mathbb{D}}$, Sergiy Smetana ${ }^{1} \mathbb{D}$, Shahida Anusha Siddiqui ${ }^{1,2} \mathbb{D}$, Sayed Mahdi Hossaini ${ }^{1} \mathbb{D}$, Volker Heinz \\ 1 and Christian Kircher ${ }^{3}$ \\ 1 DIL e.V.-German Institute of Food Technology, Prof.-von-Klitzing-Straße 7, 49610 D-Quakenbrück, \\ Germany; s.smetana@dil-ev.de (S.S.); s.siddiqui@dil-ev.de (A.S.); s.hossaini@dil-ev.de (S.H.); \\ v.heinz@dil-ev.de (V.H.) \\ 2 Technical University of Munich (TUM), Schulgasse 22, 94315 Straubing, Germany \\ 3 LI Food, Prof.-von-Klitzing-Straße 7, 49610 D-Quakenbrück, Germany; c.kircher@dil-ev.de (C.K.) \\ * Correspondence: a.profeta@dil-ev.de; Tel.: +49-5431-183-326
}

\begin{abstract}
This study clearly shows that the corona pandemic has a significant impact on consumers' eating habits. More food is eaten overall, and more convenience products such as ready meals and canned food with a longer shelf life are purchased. The consumption of alcohol and confectionery has also increased. In return, the consumption of fresh fruit and vegetables has declined. It becomes clear that families who are financially affected by the pandemic represent a vulnerable group. With the increasing duration of the pandemic, repeated lockdowns, corona-related closings of schools and kindergartens, health consequences are to be expected in the medium to long term, especially for this population group.
\end{abstract}

Keywords: Covid-19; Corona; consumer behaviour; food; health.

\section{The pandemic - a catalyst of an unhealthy diet?}

The ongoing corona pandemic affected many people worldwide by restrictions in their everyday lives. It is to highlight that the pandemic has also influenced the eating behaviour and shopping habits of consumers. Due to possible quarantine phases, consumers were concerned about which type of food and its quantities should be stored [1]. In addition, there were short-term out-of-stock situations in the food retail sector [2] for selected products (e.g. flour, pasta, disinfectants, etc.).

In this context, the Lower Saxony State Food Industry Association - LI Food ( www.li-food.de) carried out a representative online survey with 973 participants in April 2020. It was precisely analyzed which effects the corona pandemic had on food consumption, shopping behaviour and eating habits in Germany. In this context, it was investigated if more healthy or unhealthy foods were consumed. Furthermore, the aspects of sustainability and health were given special consideration in the study. Therefore, it was analyzed whether there were changes in the consumption quantity in different product categories or food waste avoidance. Besides, it was considered whether the pandemic affected the purchase of organically and locally produced products. The focus was primarily on households with children and households affected by a loss of income due to the lockdown. In general, the question arises to what extent the pandemic has accelerated diet trends or general differences in food consumption between different population groups. The next section briefly describes existing studies on the subject before presenting the methodology and the study results. 


\section{Psychological and physical effects of the pandemic and possible effects on the eating and purchasing behaviour of consumers \\ 2.1. "More food - an instrument for reducing stress"}

It is to hypothesize that the pandemic has a direct impact on people's psyche. Even in regions with a relatively low risk of infection, the population was exposed to massive risk communication and media reporting in spring 2020, which in itself is a relevant psychological stressor. Also, a not inconsiderable part of the population is affected by short-time work or unemployment or is worried about a possible job loss, which can also impact psychological well-being [3,4]. In this context, eating "more" can be a coping strategy for dealing with the pandemic and the stress it causes. The increased consumption of (alcoholic) beverages and food can represent an attempt to feel better under stress [5,6]. For example, in Italy's first lockdown, it was observed that households mainly consumed more processed "comfort foods" such as chocolate, chips and snacks $[7,8]$. The longer lockdown measures or curfews last, the more a possible increased consumption could lead to obesity with all its consequences. In other words, specifically a higher prevalence for, among other things, diabetes, coronary disease and cancer [9].

\subsection{Reduced physical activity as an amplifying factor for negative effects}

During the coronavirus pandemic, physical and sporting activities in the population in particular have declined and children and parents alike spent massively more time with computer games and online media [10]. In the current edition of the specialist journal "Nervenheilkunde", an article by the well-known neurologist Manfred Spitzer [10] anecdotally quotes a teacher as follows:

"The students, whom I was able to see again for a few hours, spent the 7 weeks almost without exception playing in front of the computer. On average they were 5-10 kilos heavier [...]."

The fatal consequences of the sketched situation becomes clear when one considers that, according to a publication in the specialist journal Lancet, a 10\% reduction in physical inactivity could avert 533,000 deaths per year worldwide [11].

\subsection{Fear as a driver for the (increased) purchase of specific product categories}

Another mediator of consumer behaviour is the associated risk with Covid-19 of falling ill or dying. Consumers could reduce their risk of infection by using delivery services or buying more packaged foods that are considered more hygienic [7]. It can also be assumed that foods with a longer shelf life will be bought (and thus fewer fresh products such as fruit and vegetables) to minimize shopping frequency and risk of infection in supermarkets. On the other hand, there is the behavioural strategy of buying healthier food to strengthen the immune system [12]. It is conceivable that this could result in an increasing demand for more fruit and vegetables or ecologically and regionally produced food. If the trend is towards more processed products with a longer shelf life, it should be noted that, among other things, this can also have side effects for consumers. Monteiro [13] and Monteiro et al. [14] argue that more processed foods have a negative impact on consumers' health status.

Another factor influencing consumer behaviour can be concerns about food shortages. It is to expect that individuals who have this fear will stockpile certain foods [7]. The Düsseldorf market research institute Innofact, which surveyed 1,037 consumers from March $24^{\text {th }}$ to $25^{\text {th }}, 2020$, found that a third of Germans bought significantly more noodles and that there was a significant increase in ready meals, toilet paper, rice, flour and kitchen rolls [15]. This behaviour changed is confirmed by scanner data from the Federal Statistical Office for calendar weeks 9 to 16, in which there was a "shopping boom" for the products just mentioned. The sketched overview of some of the study results already available shows a trend towards increased consumption and towards stockpiling and allows the assumption that the trend towards ecological and regional or healthier products may have increased. 


\subsection{Consequences of corona-related loss of income or unemployment}

In Germany, the pandemic led to increased unemployment and short-time work due to the pandemic (Homepage - Statistics of the Federal Employment Agency, n.d.). Besides, there is evidence that the lower the level of education, the higher the proportion of people who went on short-time work, unpaid vacation or unemployment. A job loss is twice as likely for someone with an intermediate level of education than for someone with a high level of education. In addition, it was mainly employees with a higher education who had the opportunity to work from home in the home office. As a result, this group was exposed to a significantly lower risk of infection than those in employment with an intermediate or low school leaving certificate [16].

A study from the UK $[3,17]$ showed that losing a job over time can lead to weight gain. Furthermore, in low-income households, the (high) price can be an obstacle to buying fruit and vegetables [18]. During the financial crisis, spending on groceries fell in many western industrialized countries, which can be ascribed to a decline in income $[19,20]$. Since the corona pandemic also represents an economic crisis, it can be assumed that the effects described can also be transferred to this.

\section{Sample and methodology of the study}

In a population survey in Germany, the DIL - German Institute for Food Technology e.V. (www.dil-ev.de) on behalf of the Lower Saxony State Food Industry Association - LI Food in the period from April $22^{\text {nd }}$ to $27^{\text {th }} 2020,973$ consumers were interviewed via an online survey about their eating, buying and cooking behaviour before and during the corona pandemic (see Table 1).

Table 1. Sociodemography of the sample $(n=973)$

\begin{tabular}{lc}
\hline & \% \\
\hline gender: male & 57.3 \\
ages groups: & \\
20-39 years & 31.5 \\
40-59 years & 38.8 \\
60+ years & 29.7 \\
household constellation: & \\
with children (0-19 years) & 23.1 \\
with children (<12 years) & 12.0 \\
two adults without children & 47.0 \\
singles & 30.5 \\
school education: & \\
low & 10.5 \\
middle & 54.1 \\
high & 35.5 \\
income loss: yes & 26.1 \\
\hline
\end{tabular}

The respondents were recruited via the consumer panel of the agency respondi ( www.respondi.com). Responsibility for household shopping was used as a screening parameter. Only people responsible for purchasing groceries or who stated that they were at least $50 \%$ of the time were allowed to participate in the study. The collected data went through a quality and plausibility check by the German Institute of Food Technology's consumer science research platform. The online questionnaire was sent to the panellists via the DIL - Quick Smart-Survey Server (www.survey.dil-ev.de).

To measure the change in the amount of food consumed due to Covid-19, a fivepoint Likert scale with the categories "much less", "slightly less", "no change", "a little more" and "much more" related. To measure the change in consumption behaviour, respondents were asked for each analyzed product group how often they consumed these foods before and during the Covid-19 pandemic. The studied product groups were fruit/vegetables, meat, fish, bread, milk, frozen goods, canned food, ready-made meals, 
biscuits/pastries, confectionery and alcohol. The response options for the consumption frequency ranged from "less than once every two weeks or never" to "daily" (see Table 2).

Table 2. Answer options on the frequency of consumption of various foods

\begin{tabular}{ll}
\hline Coding & Answer categories \\
\hline 1 & less then once every two weeks or never \\
2 & between once a week and once each two weeks \\
3 & once a week \\
4 & $2-3$ times per week \\
5 & $4-6$ times per week \\
6 & daily \\
\hline
\end{tabular}

For the analysis for each product category (see Figure 3), the mean value (based on the number coding for the response categories) before the pandemic $\left(\bar{x}_{\text {before covid-19) }}\right)$ and the mean of the change caused by the pandemic $\left(\bar{x}_{\text {change }}=\bar{x}_{\text {before Covid-19 }}-\right.$ $\bar{x}_{\text {during Covid-19) }}$ is calculated. A two-sided t-test is applied to analyze whether the consumption frequency in a product category has changed due to the corona pandemic. The $H_{0}$-hypothesis checks whether the measured change in the consumption quantity is equal to zero $\left(\mu_{\text {change }}=0\right)$. It is to highlight that the change in consumption frequency is also shown at the individual level in the result section. This is, the values of the numerical coding for the consumption frequency before and during the pandemic are subtracted from each other at the level of the individual respondent (see formula I), so that numbers of a maximum of +5 (change from "daily" to "less than once every two weeks or never ") to -5 (change from" Less than once every two weeks or never "to" Daily") are possible results (see Figure 3).

$$
\begin{aligned}
& \Delta \text { Eating frequency }= \\
& \qquad \text { Eating frequency } \text { during Covid-19 }- \text { Eating frequency }_{\text {before Covid-19 }}
\end{aligned}
$$

To measure further changes in consumer behaviour due to the corona pandemic, a 5-pole Likert scale with the answer options "much less", "a little less", "no change", a little more "and" much more "is used. The $\chi^{2}$-test is used to test the relationship between consumers' fear of not getting food and the question of whether more food will be stored during the pandemic [21].

It $\mathrm{s}$ to hypothesize that the pandemic will have stronger impact in certain household segments (see Section 4.2). Therefore, five household segments were created for the in-depth analysis (see Table 3). The presence of children in the household and the extent to which a corona-related loss of income was affected were used as segmentation variables as differentiating features. Differences in consumer behaviour of the analysed households segments are checked via a row of $\chi^{2}$-tests. 
Table 3. Sample size of the analyzed household segments

\begin{tabular}{|c|c|c|c|c|c|c|}
\hline & $\begin{array}{l}\text { Total } \\
\text { sample }\end{array}$ & $\begin{array}{l}\frac{\text { no kids \& }}{\text { no }} \\
\text { come } \\
\text { loss }\end{array}$ & $\begin{array}{l}\text { kids \& } \\
\underline{\text { no }} \text { in- } \\
\text { come } \\
\text { loss }\end{array}$ & $\begin{array}{l}\text { no kids \& } \\
\text { income } \\
\text { loss }\end{array}$ & $\begin{array}{l}\text { kids \& } \\
\text { income } \\
\text { loss }\end{array}$ & $\begin{array}{l}\text { kids } \\
<12 \text { y. \& } \\
\text { income } \\
\text { loss }\end{array}$ \\
\hline sample size & 973 & 579 & 140 & 169 & 85 & 36 \\
\hline $\begin{array}{l}\varnothing \text { household size } \\
\text { age }\end{array}$ & 2.29 & 1.82 & 4.04 & 1.79 & 3.61 & 3.33 \\
\hline 20-39 years & 31.5 & $23.8 \%$ & $46.4 \%$ & $34 ., 9 \%$ & $52.9 \%$ & $72.2 \%$ \\
\hline 40-59 years & 38.8 & $33.7 \%$ & $47.1 \%$ & $45.0 \%$ & $47.1 \%$ & $27.8 \%$ \\
\hline $\begin{array}{l}60+\text { years } \\
\text { education }\end{array}$ & 29.7 & $42.5 \%$ & $6.4 \%$ & $20.1 \%$ & - & - \\
\hline low & 10,5 & $12.4 \%$ & $5.7 \%$ & $9.5 \%$ & $7.1 \%$ & $13.9 \%$ \\
\hline middle & 54.1 & $53.7 \%$ & $54.3 \%$ & $52.1 \%$ & $60.0 \%$ & $58.3 \%$ \\
\hline high & 35.5 & $33.9 \%$ & $40.0 \%$ & $38.5 \%$ & $32.9 \%$ & $27.8 \%$ \\
\hline
\end{tabular}

$$
\begin{array}{ll} 
& 4 . \\
& 4 . \\
& \text { to } \\
& \text { en } \\
& (3 \\
& \text { fe } \\
& \text { an } \\
& p \\
\end{array}
$$

\section{Results}

\subsection{Stockpiling and the influence of risk perception}

Almost a third of respondents (31.4\%) said they stockpile more food compared to the time before the pandemic (see Table 4). Simultaneously, the fear of not getting enough food increased massively. Before Covid-19, very few of the study participants $(3 \%)$ had this fear. In contrast, this increased to almost $18 \%$ (sum of the values "often" and "occasionally") to the time of survey (see Table 5). Concerning the influence of the fear of not getting enough food on the actual stockpiling, it can be found that this fear is an immediate trigger. The greater the fear of not getting any food, the more the study participants are stockpiling $(\chi=55.164 ; d f=2, p<0.001)$.

Table 4. Does your household stock-up on food more than in the period before Covid-19?

\begin{tabular}{lc}
\hline & $\%$ \\
\hline yes & 31.4 \\
no & 68.6 \\
\hline
\end{tabular}

Table 5. Has anyone in your household been anxious about obtaining enough food to meet their requirements before and during Covid-19?

\begin{tabular}{lcc}
\hline & before Covid-19 in \% & during Covid-19 in \% \\
\hline frequently & 0.2 & 1.5 \\
occasionally & 2.7 & 16.2 \\
never & 97.1 & 82.2 \\
\hline
\end{tabular}

\subsection{Change in consumption of food overall}

As part of the study, the participants were asked directly how much their household's eating habits had changed during the Covid 19 pandemic compared to before. A central aspect here was whether more food is being eaten during the pandemic in this context. Across the entire sample, $20.5 \%$, i.e. around a fifth of the respondents, stated that "more food" was consumed in their household (sum of the values "much more" and "a little more") (see Figure 2).

When the additional consumption is analyzed in the context of different household segments, it becomes clear that there is a high degree of heterogeneity in the population in this regard (see Figure 3). In households with no children and no income loss, the increase was sub-proportional compared to the average. In contrast, it is to emphasize that there was an increased caloric intake, especially in households with children and/or pandemic-related income losses. In households with small children $(<12$ years $)$ in which 
there was a loss of income, this figure even rises to $44.4 \%$ (sum of top scores "much more" and "a little more").

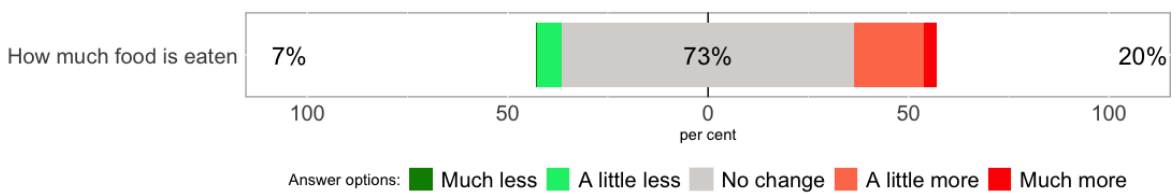

Figure 1. Change in the amount of food consumed during Covid-19.

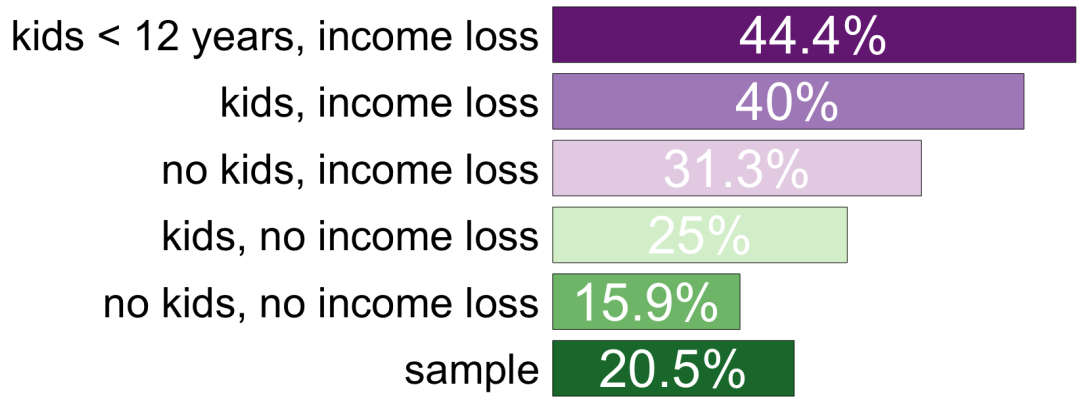

Figure 2. Share of households with an increased consumption of food overall in different household segments (top scores "much more" and "a little more").

\subsection{Change in consumption frequency of various product categories}

During the corona pandemic, there were significant decreases in the frequency of consumption of fruit/vegetables, fish and meat (see Figure 4). In contrast, there were significant increases in the categories of canned goods, ready meals, cookies/pastries, confectionery and alcohol. Thus, there was a tendency for fresh products to be partly substituted by more processed, and more durable (convenience) products or partially unhealthy foods and luxury goods (sweets, alcohol) or the latter were increasingly consumed add-on. 


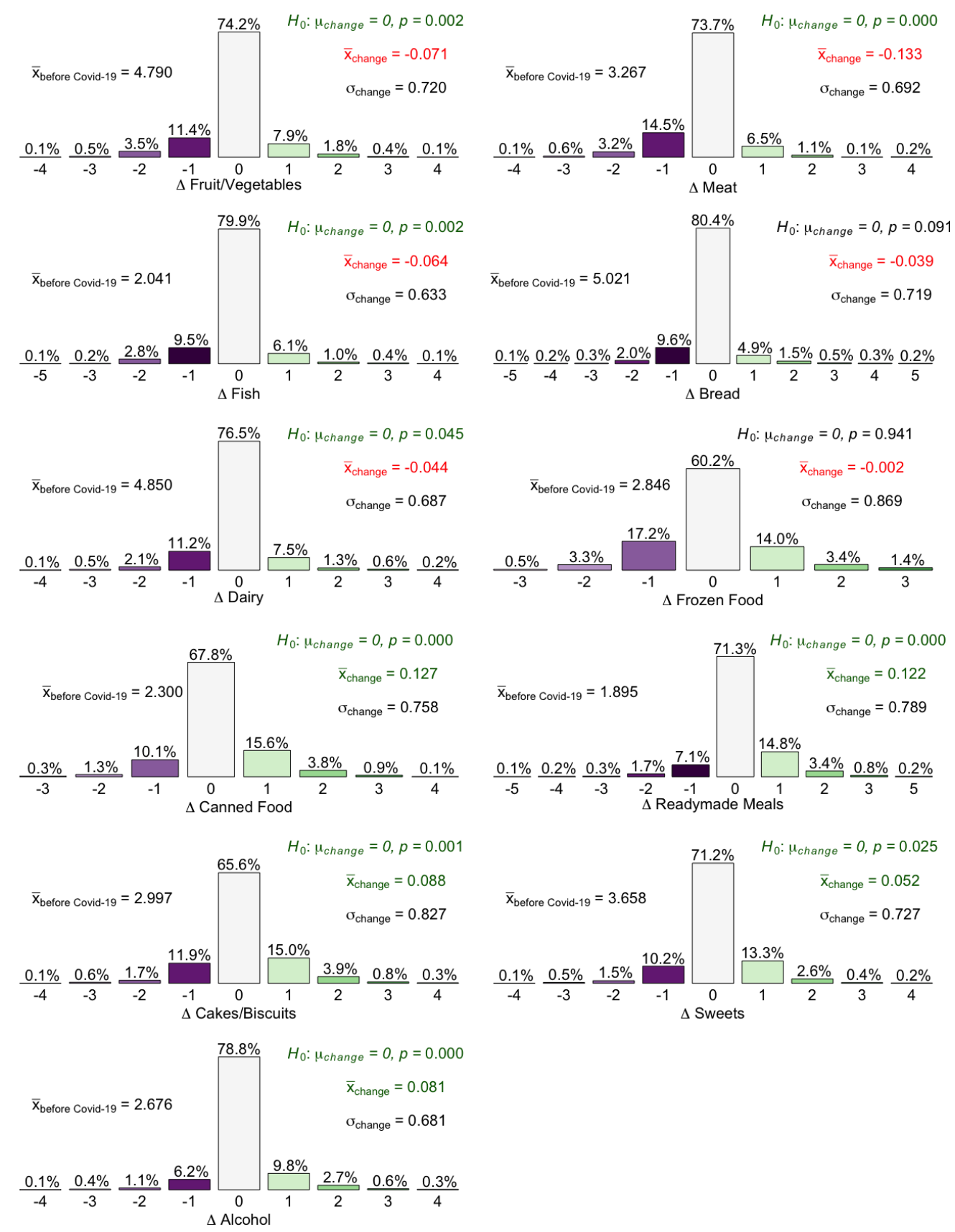

Figure 3. Change in consumption frequency in certain product categories.

Concerning the different household segments, again large group differences become apparent. While alcohol consumption rose across all respondents in $13.4 \%$ of respondents, this was only $11.5 \%$ in people without children and without loss of income. In contrast, alcohol consumption increased in $21.2 \%$ of households with children and with reduced income (see Table 6).

For the fruit and vegetables product group, it can be stated that only $10.8 \%$ stated that they consume fewer products in this category for households with children and without loss of income. Furthermore, the consumption of fruit and vegetables in this segment even increased on average during the pandemic. The opposite can be found for households with children and a loss of income (17.7\%). In households with small children, almost every fifth household (19.4\%) decreased the consumption of these healthy foods. Contrarily, households with children with no loss of income, only around $16.6 \%$ reported an increased consumption of ready-made meals. On the other hand, 
Table 6. Change in consumption frequency according to product groups and household segments (top scores)

\begin{tabular}{llllll}
\hline & sample & $\begin{array}{l}\text { no kids \& } \\
\text { no income }\end{array}$ & $\begin{array}{l}\text { kids \& } \\
\text { no income }\end{array}$ & $\begin{array}{l}\text { no kids \& } \\
\text { income } \\
\text { loss }\end{array}$ & $\begin{array}{l}\text { kids \& } \\
\text { income } \\
\text { loss }\end{array}$ \\
\hline $\begin{array}{llll}\text { loss alcohol } \\
\text { less fruits }\end{array}$ & $13.4 \%$ & $11.5 \%$ & $13.6 \%$ & $17.1 \%$ & $21.2 \%$ \\
more ready-meals & $15.5 \%$ & $13.2 \%$ & $10.8 \%$ & $16.7 \%$ & $17.7 \%$ \\
more tinned food & $20.4 \%$ & $16.6 \%$ & $15.7 \%$ & $23.6 \%$ & $28.3 \%$ \\
more frozen food & $18.8 \%$ & $16.7 \%$ & $16.4 \%$ & $20.8 \%$ & $24.7 \%$ \\
less meat & $18.4 \%$ & $16.7 \%$ & $17.8 \%$ & $20.8 \%$ & $27.8 \%$ \\
\hline
\end{tabular}

* Hinweis: Für die Produktkategorien, für welche der Mehrkonsum angegeben wird, wurden die Top-Scores „,viel me

there was an increase in $28.3 \%$ of households with children and a loss of income. A similar picture emerges for frozen goods. In the meat product category, it is noticeable that, especially in households with children and a loss of income, meat consumption has declined disproportionately (29.4\%). In households with children without loss of income, this value was only $17.8 \%$.

During the corona pandemic, there were price increases for meat and vegetables [22]. Agricultural economic research shows that lower-income households usually react more flexibly than the average household [23]. That is plausible, because households with a lower income have to calculate more precisely to get along with their financial budget. Accordingly, higher-income households ask comparatively inelastic terms. It is worth mentioning that food prices during the corona pandemic are very different across the segments perceived. For example, $63.9 \%$ of households with small children and income losses stated that they now spend more money on food compared to the pre-Covid-19 period. For households with children but no loss of income, this value was only $25.0 \%$.

\subsection{Changed eating habits in the context of the aspect of sustainability}

There were only minor changes in consumers concerning regional or organically produced food. In other words, as a result of the pandemic, there was no push towards regionally or organically produced products (see Figure 4). The changes in the positive as well as the negative direction almost compensate each other.

In the context of sustainability, however, it can be shown that a relatively large group of $26 \%$ of those surveyed stated that they throw away less food. In addition, more than a third said the extent to which they plan meals and/or their grocery list in advance has increased. Based on a -square test, a connection between the changed extent of planning and food waste avoidance could be found. The group of people who said they planned to plan "a lot more" or "more" in advance indicated disproportionately often that they threw away "a little less" or "much less" food during the pandemic $\left(\chi^{2}=139,77 ; d f=16 ; p<0,001\right)$. 


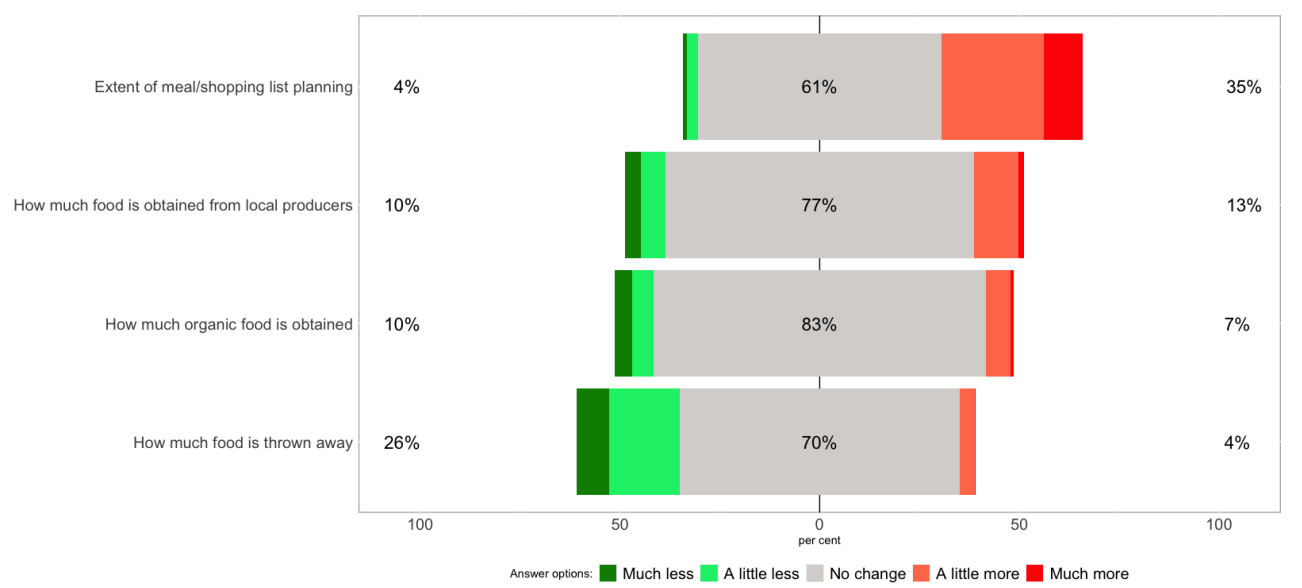

Figure 4. Change in consumer behavior due to the corona pandemic).

\section{Conclusion and recommendations to politics, industry and research}

This empirical study demonstrate that the corona pandemic has a significant influence on the eating habits of consumers. More food is eaten overall, and more convenience products such as ready meals and canned food with a longer shelf life are purchased. The consumption of alcohol and confectionery has also increased. In return, the consumption of fresh fruit and vegetables has declined.

It should be emphasized that these changes occurred to varying degrees in different household types. The overall increase in food consumption in the presence of children and corona-related income losses was much more pronounced than, for example, in households without loss of income. It is noticeable that in the households affected by budget restrictions, the "child" factor alone leads to a deterioration in the household diet. In other words, an increase in calorie intake that is well above average and a much more pronounced change in behaviour towards an increased consumption of the more unhealthy product groups. In this context, it is worrying that alcohol consumption has risen most strongly in precisely these households.Families who are financially affected by the pandemic represent a vulnerable group. With the increasing duration of the pandemic, repeated lockdowns, corona-related closings of schools and kindergartens, health consequences are expected in the medium to long term, especially for this population group. The following measures can be taken by politicians and other stakeholders related to food production to counteract this negative development:

- Keeping schools and kindergartens opened as long as possible.

This can have a direct influence on the children's nutrition through meal planning. Widespread application of the DGE quality standard (...) for healthy and sustainable catering in community facilities for children

- The quality of community catering for children must be massively increased. Freshness, health and enjoyment must be in the foreground. The caloric content of the menus must be adapted to the children's age. In addition, constant random quality control by higher-level authorities is required.

- The municipalities and districts with the support of the state governments must not act according to the standard "good and above all cheap", but actually to take money into hand for the required quality of the food.

Due to the increase in the consumption of more processed or processed products, the food industry can also increase or maintain their health value by using more gentle and improved production methods and processes (e.g. high-pressure technology, pulsed electric fields). Government support can be provided from two sides in this context. On the one hand, it makes sense to focus on sustainable and healthy food in research funding to optimize the underlying procedures and processes or, if necessary, to develop 
them. On the other hand, there is the possibility of previously voluntary labelling to set the Nutri-Score as mandatory by law. Consumers, especially when it comes to foods that are also intended for their children, quickly become clear as to whether they are looking at healthy foods or not. The study showed that a considerable part of the population feared not getting enough food during the pandemic. Therefore, it is recommended that the responsible state ministries do more educational work in non-pandemic times and generally encourage the population to always have a certain amount of food in stock for emergency to avoid a run on grocery stores in times of crisis. The extent to which the communication between political actors in the media has contributed to the increased fear or not needs further research.

other points: sample size, check with upcoming Gfk-data,

Author Contributions: For research articles with several authors, a short paragraph specifying their individual contributions must be provided. The following statements should be used "Conceptualization, X.X. and Y.Y.; methodology, X.X.; software, X.X.; validation, X.X., Y.Y. and Z.Z.; formal analysis, X.X.; investigation, $X . X . ;$ resources, $X . X . ;$ data curation, $X . X . ;$ writingoriginal draft preparation, X.X.; writing-review and editing, X.X.; visualization, X.X.; supervision, X.X.; project administration, X.X.; funding acquisition, Y.Y. All authors have read and agreed to the published version of the manuscript.", please turn to the CRediT taxonomy for the term explanation. Authorship must be limited to those who have contributed substantially to the work reported.

Funding: Please add: "This research received no external funding" or "This research was funded by NAME OF FUNDER grant number XXX." and and "The APC was funded by XXX". Check carefully that the details given are accurate and use the standard spelling of funding agency names at https:/ / search.crossref.org/funding, any errors may affect your future funding.

Institutional Review Board Statement: In this section, you should add the Institutional Review Board Statement and approval number, if relevant to your study. You might choose to exclude this statement if the study did not require ethical approval. Please note that the Editorial Office might ask you for further information. Please add "The study was conducted according to the guidelines of the Declaration of Helsinki, and approved by the Institutional Review Board (or Ethics Committee) of NAME OF INSTITUTE (protocol code XXX and date of approval)." OR "Ethical review and approval were waived for this study, due to REASON (please provide a detailed justification)." OR "Not applicable" for studies not involving humans or animals.

Informed Consent Statement: Please add "Informed consent was obtained from all subjects involved in the study." OR "Patient consent was waived due to REASON (please provide a detailed justification)." OR "Not applicable" for studies not involving humans.

Data Availability Statement: Please refer to suggested Data Availability Statements in section "MDPI Research Data Policies" at https:/ / www.mdpi.com/ethics.

Acknowledgments: In this section you can acknowledge any support given which is not covered by the author contribution or funding sections. This may include administrative and technical support, or donations in kind (e.g., materials used for experiments).

Conflicts of Interest: Declare conflicts of interest or state "The authors declare no conflict of interest." Authors must identify and declare any personal circumstances or interest that may be perceived as inappropriately influencing the representation or interpretation of reported research results. Any role of the funders in the design of the study; in the collection, analyses or interpretation of data; in the writing of the manuscript, or in the decision to publish the results must be declared in this section. If there is no role, please state "The funders had no role in the design of the study; in the collection, analyses, or interpretation of data; in the writing of the manuscript, or in the decision to publish the results".

Sample Availability: Samples of the compounds ... are available from the authors.

\section{Abbreviations}

The following abbreviations are used in this manuscript: 
MDPI Multidisciplinary Digital Publishing Institute

DOAJ Directory of open access journals

294 TLA Three letter acronym

LD Linear dichroism

\section{Appendix A}

296 Appendix A.1

297

298

299

300

301

The appendix is an optional section that can contain details and data supplemental to the main text-for example, explanations of experimental details that would disrupt the flow of the main text but nonetheless remain crucial to understanding and reproducing the research shown; figures of replicates for experiments of which representative data are shown in the main text can be added here if brief, or as Supplementary Data. Mathematical proofs of results not central to the paper can be added as an appendix.

\section{Appendix B}

All appendix sections must be cited in the main text. In the appendices, Figures, Tables, etc. should be labeled, starting with "A"—e.g., Figure A1, Figure A2, etc.

\section{References}

1. Dammeyer, J. An explorative study of the individual differences associated with consumer stockpiling during the early stages of the 2020 Coronavirus outbreak in Europe. Personality and Individual Differences 2020, 167, 110263. doi:10.1016/j.paid.2020.110263.

2. Liu, S. Food Supply Pressure in France and Germany During COVID-19: Causes from Manufacturing. Journal of Agriculture, Food Systems, and Community Development 2020, 9, 1-4. doi:10.5304/jafscd.2020.094.007.

3. Monsivais, P.; Martin, A.; Suhrcke, M.; Forouhi, N.G.; Wareham, N.J. Job-loss and weight gain in British adults: Evidence from two longitudinal studies. Social Science and Medicine 2015, 143, 223-231. doi:10.1016/j.socscimed.2015.08.052.

4. van Hal, G. The true cost of the economic crisis on psychological well-being: A review, 2015. doi:10.2147/PRBM.S44732.

5. Conway, T.L.; Vickers, R.R.; Ward, H.W.; Rahe, R.H. Occupational stress and variation in cigarette, coffee, and alcohol consumption. Journal of Health and Social Behavior 1981, 22, 155-165. doi:10.2307/2136291.

6. Laitinen, J.; Ek, E.; Sovio, U. Stress-related eating and drinking behavior and body mass index and predictors of this behavior. Preventive Medicine 2002, 34, 29-39. doi:10.1006/pmed.2001.0948.

7. Bracale, R.; Vaccaro, C.M. Changes in food choice following restrictive measures due to Covid-19. Nutrition, Metabolism and Cardiovascular Diseases 2020, 30, 1423-1426. doi:10.1016/j.numecd.2020.05.027.

8. Scarmozzino, F; Visioli, F. Covid-19 and the subsequent lockdown modified dietary habits of almost half the population in an Italian sample. Foods 2020, 9. doi:10.3390/foods9050675.

9. Swinburn, B.A.; Kraak, V.I.; Allender, S.; Atkins, V.J.; Baker, P.I.; Bogard, J.R.; Brinsden, H.; Calvillo, A.; De Schutter, O.; Devarajan, R.; Ezzati, M.; Friel, S.; Goenka, S.; Hammond, R.A.; Hastings, G.; Hawkes, C.; Herrero, M.; Hovmand, P.S.; Howden, M.; Jaacks, L.M.; Kapetanaki, A.B.; Kasman, M.; Kuhnlein, H.V.; Kumanyika, S.K.; Larijani, B.; Lobstein, T.; Long, M.W.; Matsudo, V.K.; Mills, S.D.; Morgan, G.; Morshed, A.; Nece, P.M.; Pan, A.; Patterson, D.W.; Sacks, G.; Shekar, M.; Simmons, G.L.; Smit, W.; Tootee, A.; Vandevijvere, S.; Waterlander, W.E.; Wolfenden, L.; Dietz, W.H. The Global Syndemic of Obesity, Undernutrition, and Climate Change: The Lancet Commission report, 2019. doi:10.1016/S0140-6736(18)32822-8.

10. Prof, K.; Spitzer, M. Die Geschichte von 2 Pandemien. Editorial Nervenheilkunde 2020, 39, 698-703. doi:10.1055/a-1193-8248.

11. Wen, C.P.; Wu, X. Stressing harms of physical inactivity to promote exercise, 2012. doi:10.1016/S0140-6736(12)60954-4.

12. Rodríguez-Pérez, C.; Molina-Montes, E.; Verardo, V.; Artacho, R.; García-Villanova, B.; Guerra-Hernández, E.J.; Ruíz-López, M.D. Changes in Dietary Behaviours during the COVID-19 Outbreak Confinement in the Spanish COVIDiet Study. Nutrients 2020, 12, 1730. doi:10.3390/nu12061730.

13. Monteiro, C.A. Nutrition and health. The issue is not food, nor nutrients, so much as processing, 2009. doi:10.1017/S1368980009005291.

14. Monteiro, C.A.; Levy, R.B.; Claro, R.M.; De Castro, I.R.R.; Cannon, G. Increasing consumption of ultra-processed foods and likely impact on human health: Evidence from Brazil. Public Health Nutrition 2011, 14, 5-13. doi:10.1017/S1368980010003241.

15. Innofact. INNOFACT Corona Studie: Wer hamstert eigentlich die Nudeln? - Innofact, 2020.

16. Naumann, E.; Möhring, K.; Reifenscheid, M.; Wenz, A.; Rettig, T.; Lehrer, R.; Krieger, U.; Juhl, S.; Friedel, S.; Fikel, M.; Cornesse, C.; Blom, A.G. COVID-19 policies in Germany and their social, political, and psychological consequences. European Policy Analysis 2020, p. epa2.1091. doi:10.1002/epa2.1091.

17. Hendrickson, D.; Smith, C.; Eikenberry, N. Fruit and vegetable access in four low-income food deserts communities in Minnesota. Agriculture and Human Values 2006, 23, 371-383. doi:10.1007/s10460-006-9002-8.

18. Cassady, D.; Jetter, K.M.; Culp, J. Is Price a Barrier to Eating More Fruits and Vegetables for Low-Income Families? Journal of the American Dietetic Association 2007, 107, 1909-1915. doi:https:/ / doi.org/10.1016/j.jada.2007.08.015. 
19. Antentas, J.M.; Vivas, E. Impacto de la crisis en el derecho a una alimentación sana y saludable. Informe SESPAS 2014. Gaceta Sanitaria 2014, 28, 58-61. doi:10.1016/j.gaceta.2014.04.006.

20. Vlontzos, G.; Duquenne, M. Identification of Decision Making for Food Under Economic Crisis: The Case of Greece. Procedia Technology 2013, 8, 306-314. doi:10.1016/j.protcy.2013.11.041.

21. Hair, J.; Black, W.; Babin, B.; Anderson, R. Multivariate Data Analysis: A Global Perspective. In Multivariate Data Analysis: A Global Perspective; 2010; Vol. 7th.

22. Akter, S. The impact of COVID-19 related 'stay-at-home' restrictions on food prices in Europe: findings from a preliminary analysis. Food Security 2020, 12, 719-725. doi:10.1007/s12571-020-01082-3.

23. Thiele, S.; Weiss, C. Consumer demand for food diversity: Evidence for Germany. Food Policy 2003, 28, 99-115. doi:10.1016/S03069192(02)00068-4. 